\title{
Produção da cidade: quais dados para quais questões?
}

[ Urban fabric: which questions for which data?

\section{Fabien Mazenod ${ }^{\mathrm{I}}$}

\section{Vanessa Moura de Lacerda Teixeira ${ }^{2}$}

\section{Carolina Moretti Fonseca ${ }^{3}$}

Texto traduzido do francês pelas autoras.

RESUMO $\mathrm{O}$ artigo é o resultado do seminário "Dinâmicas de urbanismo e representações espaciais: heurística dos dados e contexto”, organizado no âmbito do projeto USP-Cofecub entre as universidades de Lyon e de São Paulo. Propõe-se explorar os métodos e as fontes dos dados utilizados por três doutorandos que tratam da produção da cidade em diferentes trabalhos de campo no Brasil, na Itália e na França. Cada posicionamento é dirigido pela especificidade da pesquisa, do estado da arte no local do trabalho de campo e, sobretudo, pelo nível de análise da produção da cidade escolhido: o ator social envolvido, os meios e o território. Esses níveis possibilitaram estruturar questões específicas a fim de explorar dados diferentes para contribuir para uma compreensão global do fenômeno acerca da produção da cidade. P PALAVRAS-CHAVE · Produção da cidade; dados; método; fontes. - ABSTRACT - This article is the result of the seminar organized for the project USP-COFECUB between universities of Lyon and São Paulo, entitled "Dynamic planning and spatial representations: heuristic data and context”. It highlights the methods and sources used by three doctoral students that deal with the production of the city on different field researches in Brazil, in Italy and in France. Each research is oriented by its particularities, the state of science in its own place, but mainly by the level of analysis of the city production, used by the researcher: the actor, the means and the territory. These levels are forcing to ask specific questions, to use different data to contribute to a comprehensive understanding of the global phenomenon of the production of the city. . KEYWORDS - Urban production; data; method; sources.

Recebido em 2 I de março de 2016

Aprovado em 5 de dezembro de 2016

TEIXEIRA, Vanessa Moura de Lacerda; FONSECA, Carolina Moretti; MAZENOD, Fabien. Produção da cidade: quais dados para quais questões?. Revista do Instituto de Estudos Brasileiros, Brasil, n. 65, p. I59-I76, dez. 2016.

DOI: http://dx.doi.org/Io.II6o6/issn.23I6-90IX.voi65pI59-I76

I Université Jean Moulin Lyon 3 (Lyon, França).

2 Université Jean Moulin Lyon 3 (Lyon, França).

3 Université Jean Moulin Lyon 3 (Lyon, França). 
A produção da cidade é, neste trabalho, compreendida como um processo de transformação do espaço tomado por diferentes atores que mobilizam meios diversos para renovar o tecido urbano ou estendê-los ao território4.Três níveis de estudo da produção da cidade foram então definidos: o ator social envolvido, os meios e o território.

$\mathrm{O}$ ator é uma entidade agindo na cidade. São pessoas e instituições que possuem um papel importante na organização do espaço, que intervêm direta ou indiretamente na elaboração dos projetos de planejamento5. Esses atores utilizam mecanismos de gestão urbana a fim de responder aos interesses da produção da cidade contemporânea. Os meios podem ser financeiros, imobiliários, regulamentares ou de gestão. Entretanto, eles são sempre precedidos por um estatuto jurídico que define e dimensiona suas aplicações. Esses meios são aplicados num território ocupado por um grupo humano que dele se apropria de maneiras diversas, principalmente políticas e jurídicas ${ }^{6}$. Assim, de acordo com a apropriação por determinados atores mobilizando os próprios meios, o território é apreendido e concebido de diferentes maneiras. Essa definição do território como "espaço apropriado" é compartilhada por certo número de geógrafos franceses?.

Os três níveis de análise - atores sociais, meios e território - suscitam diferentes questionamentos para compreender a produção da cidade. A fim de responder a esses questionamentos, necessitamos de dados específicos. Essa contribuição apresenta a maneira pela qual as três teses de doutorado questionam a produção da cidade nesses três níveis, utilizando-se de dados diferentes, mas complementares. As escolhas foram impostas pela formação e sensibilidade de cada doutorando, e também pelas áreas de pesquisa escolhidas.

4 BOINO, Paul. La production de la ville. Paris: Éditions Parenthèses, 2009; GAUTHIEZ, Bernard; BURGEL, Guy. Espace urbain: vocabulaire et morphologie. Paris: Centre des Monuments Nationaux, 2003.

5 GUMUCHIAN, Hervé (Coord.). Les acteurs, ces oubliés du territoire. Paris: Anthropos; 2003; WACKERMANN, Gabriel; BATTIAU, Michel. Dictionnaire de géographie. Paris: Ellipses Marketing, 2005.

6 KLEINSCHMAGER, Richard; PUMAIN, Denise; PAQUOT, Thierry. Dictionnaire la ville et l'urbain. Paris: Economica, 2006.

7 LUSSAULT, Michel; LEVY, Jacques. Dictionnaire de la géographie et de l'espace des sociétés. Tours: Belin, 2003. 
Para estudar a produção da cidade de Roma durante o fascismo, Fabien Mazenod $^{8}$ escolheu analisar a ação e a lógica de um operador importante, o INA (Istituto Nazionale delle Assicurazioni, uma sociedade de assistência). Nessa linha de pesquisa, em que a literatura científica é abundante, a abordagem do ator social permite um conhecimento mais detalhado da produção urbana e a reconstituição da análise política e ideológica do processo. Para essa forma de estudar a produção da cidade, uma presença assídua nos arquivos da cidade e sobretudo nos arquivos de empresas se mostrou necessária.

Para compreender como as operações de urbanismo consorciadas se realizam em Lyon, no caso da Confluence, e em São Paulo, no caso da Operação Urbana Consorciada Água Espraiada - Oucae, Carolina Moretti Fonseca9 explora os meios jurídicos ligados aos dois casos e também os dados de valorização imobiliária ligada à transformação do espaço planejado.

Vanessa Moura de Lacerda Teixeira ${ }^{\text {Io }}$ estudou a produção da cidade a partir do território. A noção de território é vasta e, no âmbito de seu trabalho, a pesquisadora escolheu analisá-lo pela sua apropriação e como configuração espacial ${ }^{\text {II }}$ para compreender as mudanças ocorridas nas zonas naturais e antrópico-naturais através da urbanização dos municípios da Região dos Lagos, no estado do Rio de Janeiro, desde os anos I940. Ainda que a literatura sobre a abordagem "cidade e meio ambiente" seja abundante, faltam trabalhos acerca dessas relações na região estudada. $\mathrm{O}$ olhar histórico e espacial é a palavra-chave da construção de dados a partir de fontes de diferentes domínios disciplinares e instituições.

\section{DADOS HISTÓRICOS E ARQUIVOS EMPRESARIAIS PARA O ESTUDO DO PAPEL DE UM ATOR NA PRODUÇÃO DA CIDADE}

Para estudar as dinâmicas urbanas de Roma no período entreguerras, um ator na fabricação da cidade foi escolhido como objeto de estudo. Ainda que, durante a administração fascista da cidade (I922-I943), as periferias romanas (arredores) tenham se expandido consideravelmente e o centro histórico tenha sido modificado pela renovação urbana, poucos estudos foram realizados sobre os atores responsáveis

8 MAZENOD, Fabien. Fabriquer la Rome fasciste. L'action de l'Istituto Nazionale delle Assicurazioni (INA). Investisseur immobilier et financeur de l'aménagement urbain. Tese (Doutorado). Lyon: Université Jean Moulin (Lyon 3), 20I4. Disponível em: 〈www.theses.fr/20I4LYO30042〉. Acesso em: out. 2016.

9 FONSECA, Carolina M. Les enjeux fonciers de la production de la ville contemporaine et les outils juridiques à service de l'aménagement urbain: étude comparative entre les opérations urbaines "Confluence”, à Lyon et “Água Espraiada”, à São Paulo, entre 200I et 20I3. Tese (Doutorado em andamento). Lyon: Université Jean Moulin (Lyon 3), 2016.

Io TEIXEIRA, Vanessa M. de L. L'urbanisation autour de la lagune Araruama, etat de Rio de Janeiro, Brésil: dynamiques spatiales et enjeux environnementaux. Tese (Doutorado). Lyon: Université Jean Moulin (Lyon 3), 20I6. Disponível em: 〈www.theses.fr/sI5523I〉. Acesso em: out. 2016.

II Ibidem. 
por essas dinâmicas urbanas ${ }^{\mathrm{I2}}$. Assim, foi feita a escolha de estudar a ação e as motivações de um operador importante, o Istituto Nazionale delle Assicurazioni (INA), uma companhia seguradora que foi responsável pelo desenvolvimento de certas partes da cidade construindo edifícios e também financiando projetos conduzidos por outros operadores, entre os quais o Gouvernorat de Roma, o poder municipal fascista.

Qual é o papel do INA na produção da cidade de Roma no período entreguerras? Aqui está a pergunta principal que guiou o projeto. Para respondê-la, dados variados foram reunidos a partir de arquivos diversos. No vasto campo de pesquisa romana, sobre o qual vários estudos urbanos já foram realizados, o pesquisador tem que achar novos objetos de estudo e, especialmente, fontes de primeira mão ainda inexploradas.

Os arquivos de empresas têm um enorme potencial científico, uma nova frente de exploração de dados e de informações para os pesquisadores que estão interessados na produção da cidade. $\mathrm{O}$ acesso aos arquivos de empresas é uma dificuldade real, mas que pode ser superada visto que certas companhias, especialmente os grupos maiores, têm um serviço (departamento) de arquivos acessível aos pesquisadores mediante autorização. Na Itália, muitos esforços foram feitos junto a empresas e arquivos públicos para colecionar, preservar e disponibilizar documentos. Assim, nos arquivos centrais do Estado foi possível encontrar os fundos (coleções) de numerosas empresas paraestatais (ferroviária, mineradora, rodoviária etc.), que influenciaram, pelas suas ações territoriais, as dinâmicas espaciais (construção civil e extensão das redes de transporte e de comunicação) a partir da instalação de unidades de produção, de moradias para os empregados etc. Além disso, o Ministério Italiano de Cultura e Turismo desenvolveu o portal Archivi d'Impresa para a coleção e a difusão dos arquivos das empresas italianas ${ }^{\mathrm{T}}$. Foram encontradas notas nas Coleções de Arquivos de mais de 2 mil empresas que trabalham na Itália, dos maiores conglomerados aos mais modestos. As pesquisas são feitas através do nome e também através da área geográfica e por período cronológico.

Para começar a pesquisa, um número significante de dados foi coletado junto aos arquivos da empresa seguradora, com o objetivo de entender a sua dinâmica operacional (a montagem de operações de urbanismo pela empresa, por exemplo). Por montagem de uma operação de urbanismo nós entendemos a organização financeira e operacional dos trabalhos. Eles são, no princípio contratos concluídos entre a empresa e os sócios (autoridades públicas para a construção de estradas, por exemplo), empresas de construção civil, arquitetos etc. Esses contratos nos informam sobre as ligações técnicas e financeiras entre a empresa e os outros operadores da cidade. Comparando os contratos, as especificações, com os relatórios das visitas

I2 Nós podemos citar, não obstante, sobre o caso do Istituto Autonomo per Le Case Popolari e da Unione Edilizia Nazionale: BARTOLINI, Francesco. Roma Borghèse. La casa e i ceti medi tra le due guerre. Rome: Laterza, $200 \mathrm{.}$ Também, sobre o Banco de Itália, o trabalho de: DOTI, Gerardo; MARINO, Angela. La Banca d’Italia e l'attività edilizia per Roma capitale: il progetto di ricerca. Roma moderna e contemporanea, n. 3, 2002.

I3 ARCHIVI D'IMPRESA. Ministero dei beni e delle attivita' culturali e del turismo. Sistema Archivistico Nazionale - SAN. Disponível em: <http://www.imprese.san.beniculturali.it/web/imprese/ home;jsessionid=2792B854D5C3D35B22I7E8Co5D2A4D5A.sanimprese_JBOSS >. Acesso em: out. $20 I 6$. 
de acompanhamento ao local dos trabalhos, nós podemos julgar o progresso do local de construção e o respeito com os compromissos assumidos, em particular os financeiros. Os balancetes anuais da empresa também foram de grande ajuda para entender a estrutura financeira da mesma, o peso e a natureza de seus investimentos na economia da cidade. Nós assim demonstramos que o investimento em bens imóveis, feito pelo INA, era relativamente baixo em relação aos investimentos do governo ( $8 \%$ do investimento total do instituto, em média, contra $36 \%$ do orçamento público entre I922 e I944). Nos arquivos de bens imóveis do instituto são mantidos os documentos cartográficos e iconográficos das construções da empresa no território romano. Encontramos projetos volumétricos, plantas baixas de cada andar, cortes longitudinais, projetos de fachadas e fotografias históricas. Um abrangente corpo iconográfico pôde assim ser constituído para todo o conjunto de bens imobiliários do INA, entre I9I2 e I945, na cidade de Roma.

Depois do estabelecimento do corpo de operações de urbanismo empreendido pelo INA, foram coletados nos arquivos públicos os elementos esclarecedores do contexto político, econômico e social das intervenções. Junto aos arquivos municipais de Roma (Archivio Storico Capitolino), foram encontradas as deliberações do Gouvernorat de Roma (Executivo municipal), as notificações dos comitês municipais competentes (comissões), que permitiram elucidar as políticas urbanas conduzidas pela municipalidade e as operações de urbanismo conduzidas em parceria público-privada: o trabalho de renovação do centro da cidade (sventramenti) e a construção de alojamentos subvencionados para acomodar os funcionários públicos (case convenzionate). Os arquivos da Secretaria de Assistência Social do Gouvernorat contêm informação muito preciosa a propósito da indenização, da expulsão e da realocação de famílias desalojadas pela renovação urbana. Eles dispõem de informações sobre as famílias afetadas (dados cadastrais) com o nome e a profissão do chefe da família, sua composição, as características da unidade habitacional destruída, indicações sobre a renda da família, a indenização pretendida e efetivamente depositada, e se a família solicita ou não seu realojamento em um novo alojamento de habitação social. São também conservados todos os pedidos de alojamento, de reclamações e as deliberações de ajuda social. O estudo desse arquivo recentemente aberto ao público refuta duas afirmações admitidas pela comunidade científica: a de que o centro histórico de Roma antes da renovação era povoado de forma homogênea por casas muito modestas; e a de que foi grande o movimento das populações do centro histórico para os borgate (núcleos residenciais na periferia romana).

Os arquivos municipais de Roma iniciaram um trabalho importante de revisão e digitalização dos mapas históricos da cidade como também das fotografias históricas. Trata-se certamente de uma porção minúscula da produção de mapas para a cidade de Roma, mas, graças ao trabalho de arquivos, o pesquisador pode ter acesso a uma coleção rica e prática do período que se inicia no século XVI até nossos dias, que, todavia, esconde disparidades fortes. A maior parte dos mapas disponíveis para consulta é do período de I870-I900 sobre o desenvolvimento de redes de transporte e serviços técnicos urbanos, mas há poucos documentos datando dos anos I9IO-I920. $\mathrm{O}$ arquivo privilegia o período fascista, em particular os planos de desenvolvimento 
de certas zonas da cidade depois de I93I, e o inventário fotográfico versa sobre os baracche (moradia informal) da municipalidade iniciada nos anos I928.

Junto aos Arquivos Centrais do Estado (Archivio Centrale dello Stato), foram encontrados relatórios feitos pelo Gouvernorat e pelos comitês municipais para Mussolini, que tinha o controle supremo do urbanismo da capital. Além disso, numerosas cartas e telegramas trocados entre os dirigentes do INA e o secretário particular de Mussolini foram reunidas, mostrando outra faceta da relação entre a empresa e o poder, outro papel do INA na produção da cidade: o financiamento das operações de urbanismo e de planejamento do território. De fato, o INA financiou a renovação urbana como uma instituição de crédito, mas também o subsídio agrícola ou a expansão das redes rodoviária e ferroviária, concedendo numerosos empréstimos ao Gouvernorat de Roma e também para as municipalidades e para as províncias de toda a Itália. O poder fascista se apropriou da empresa para financiar e concretizar suas políticas urbanas e de planejamento de cidades em todo o país. Cartas e relatórios recolhidos nos arquivos públicos permitem elucidar a relação triangular entre o INA, Mussolini e o Gouvernorat de Roma para esclarecer a produção da cidade de Roma, avaliar melhor o equilíbrio de forças entre as três operadoras e minimizar a parte do não dito, sempre presente nas relações bilaterais, principalmente durante a administração fascista da municipalidade de Roma, que contém a chave para entender o jogo dos atores e a fabricação material da capital.

Estudar a produção da cidade partindo da lógica de um operador é um posicionamento científico que exige recorrer aos seus arquivos. E, para tanto, o pesquisador enfrenta várias dificuldades. Além da acessibilidade física e prática às fontes, a dificuldade principal é cruzar os elementos obtidos junto aos arquivos do operador com outros dados, tudo isso em um movimento constante e interativo entre fontes e questionamentos, especialmente porque os arquivos das empresas são muito pouco explorados. Para a pesquisa doutoral conduzida sobre a produção da cidade de Roma durante o fascismo, o estudo da ação e da lógica de um operador urbano permitiu refinar o quadro da história do urbanismo romano, monopolizado pela análise política, ideológica e arquitetural, restituindo os desafios e os interesses de cada um dos operadores na produção da cidade. Para conhecer o processo de formação das cidades na Europa e no resto do mundo, é preciso estudar a produção da cidade sob o enfoque do operador urbano.

\section{QUAIS REGRAS DE PLANEJAMENTO URBANO SÃO NECESSÁRIAS PARA ENTENDER A PRODUÇÃo da CIDADE?}

No Brasil, como na França, as operações de planejamento urbano realçam o papel do urbanista e do administrador público. Na França, a prática do planejamento é mais antiga e é guiada pelos conhecimentos geográficos universitários desde o século XIX. No Brasil, essa prática é mais recente e fomentada pela transferência do conhecimento geográfico estrangeiro. Novas formas de planejamento urbano, sobretudo encampadas pelas administrações das grandes cidades, são estudos de 
caso interessantes para a análise da utilização e da circulação do conhecimento geográfico no discurso e na prática.

Uma dimensão que não pode ser subconsiderada é a normativa. As regras de planejamento urbano têm papel fundamental no desenvolvimento das cidades, e entender seu conteúdo e os impactos de sua aplicação é um desafio científico e metodológico. A intenção deste trabalho é explorar, a partir da análise de dois casos concretos, os dados necessários para fazer face a esse desafio.

O eixo desse raciocínio, entendido como um dos modos pelos quais é possível urbanizar um território, levará em consideração os diversos aspectos que se cruzam para produzir a qualidade urbana ${ }^{\mathrm{I} 4}$. As vertentes legais e de gestão serão a ele adicionadas visando a uma análise mais completa.

A cada consideração, uma pergunta será feita e, a cada resposta, serão indicados os dados utilizados para explicá-la. Um quadro sinóptico resumirá a análise. Esse exercício será feito a partir de dois exemplos: a Operação Urbana Consorciada Água Espraiada, no Brasil, e a Zone d'Aménagement Concerté Confluence - ZAC ${ }^{\text {I5 }}$, na França.

O aspecto normativo, entendido como essencial para o planejamento das cidades, contribui com o arcabouço jurídico necessário para que a operação urbana possa ser realizada em consonância com as demais normas aplicáveis ao território ${ }^{\mathrm{I}}$. Conhecer os textos normativos sobre território, no Brasil e na França, é, sobretudo, possível graças à exploração de fontes digitais. A doutrina é acessível a partir de referências bibliográficas ${ }^{\mathrm{I}}$.

A gestão do território como objeto de estudo pode ter grande amplitude. Para

I4 A qualidade urbana é uma noção muito complexa, pois mistura (envolve) considerações econômicas, ambientais, políticas e sociais. Uma qualidade do planejamento urbano tem que satisfazer as necessidades de habitantes e de usuários, tem que permitir o acesso multimodal às funções urbanas (escritórios), favorecer as trocas e o bem-estar. A qualidade urbana é pensada, assim, na escala articulada do projeto urbano ao território aglomerado. DUMONT, Marc; ANDRIEU, Dominique. Qualité urbaine et ville durable à l'épreuve du renouvellement urbain. L'exemple du Grand Projet de Ville Malakoff Pré Gauchet à Nantes. Norois, n. I98, 2066; BARBARINO-SAULNIER, Natalia. De la qualité de vie au diagnostic urbain, vers une nouvelle méthode d'évaluation: le cas de la ville de Lyon, sous la direction de Franck Scherrer. Lyon: Université de Lyon, 2005; BOURDEAU-LEPAGE, Lise. Regards sur la ville, Paris: Economica, 20I2; CUNHA, Antonio da; GUINAND, Sandra. Qualité urbaine, justice spatiale et projet. Lausanne: Presses Polytechniques et Universitaires romandes, 20I4.

I5 Zone d'Aménagement Concerté - ZAC corresponde, no direito brasileiro, ao perímetro de uma operação urbana.

I6 SILVA, José Alfonso da. Direito urbanístico brasileiro. São Paulo: Malheiros Editores, 2oI2; FERNANDES, Edésio; VARLEY, Ann. Illegal cities: law and urban change in developing countries. London: Zed Books, I998; OLBERTZ, Karlin. Operação urbana consorciada. Belo Horizonte: Fórum, 20I2; RENARD, Vincent. Plans d'urbanisme et justice foncière. Paris: Presses Universitaires de France, I992; SOLER-COUTEAUX, Pierre; CARPENTIER, Elise. Droit de l'urbanisme. Paris: Dalloz, 20I3; ZEPF, Marcus (Coord). Concerter, gouverner et concevoir les espaces publics urbains. Lausanne: Presses Polytechniques et Universitaires Romandes, 2004.

I7 SILVA, José Alfonso da, op. cit.; FERNANDES, Edésio; VARLEY, Ann, op. cit.; OLBERTZ, Karlin, op. cit.; RENARD, Vincent, op. cit.; SOLER-COUTEAUX, Pierre; CARPENTIER, Elise, op. cit.; ZEPF, Marcus, op. cit. 
entender a administração das operações urbanas escolhidas é necessário inserir-se em suas lógicas individuais e operacionais, o que é possível a partir das atas das reuniões deliberativas e dos relatórios de acompanhamento, em que estão registradas as decisões e as motivações e dos tomadores de decisões.

A variável econômica do planejamento urbano, nesta análise, será restrita à questão fundiária antes e depois da operação urbana, mais exatamente às aquisições das áreas necessárias para intervenções previstas pela operação, e também à valorização dos bens imóveis atribuída a essas intervenções, que podem ser traduzidas por um ganho de capital que se evidencia nos preços de mercado dos referidos bens. $\mathrm{O}$ acompanhamento orçamentário da operação urbana e as licitações são essenciais para ilustrar essa dimensão.

O respeito ao meio ambiente é um aspecto particular das operações de planejamento urbano, porque é ao mesmo tempo condicionado pelo conjunto de regras urbanísticas e pelos valores da sociedade na qual estão inseridas. Os documentos oficiais de apresentação das operações e de suas intervenções realçam essa constatação. $\mathrm{O}$ aspecto humano, mensurado pela cidade em escala humana, enfrenta os mesmos desafios.

A dimensão política, bastante vasta, será traduzida pelo papel dos agentes públicos e privados envolvidos nos processos de planejamento urbano. Vários interesses estão em jogo, e a imprensa coloca-se como uma espectadora atenta. $\mathrm{O}$ testemunho dos empregados estatais também pode ajudar a explicar algumas indagações.

O aspecto social - razão de ser das políticas públicas - aparece em várias ações de planejamento urbano. Ele justifica e motiva um grande número de iniciativas. Seu caráter abrangente apresenta, algumas vezes, uma difícil execução, apesar de as deliberações e regras serem muito precisas. Os registros das decisões e os relatórios das reuniões do conselho deliberativo das operações urbanas são preciosos como elementos iniciais de análise.

O quadro I permite a visualização das perguntas e dos respectivos dados aplicados a cada um dos estudos de caso 


\begin{tabular}{|c|c|c|c|c|}
\hline Dimensão & Questão & Informação & Oucae & Confluence \\
\hline \multirow[b]{2}{*}{ Jurídica } & Quais regras? & Leis & $\mathrm{x}$ & $\mathrm{x}$ \\
\hline & Qual jurisprudência? & Bibliografia & $\mathrm{x}$ & $\mathrm{x}$ \\
\hline \multirow{3}{*}{ De gestão } & Como são produzidas & Arquivos & & $\mathrm{x}$ \\
\hline & Como são executadas? & Documentos internos & $\mathrm{x}$ & \\
\hline & Como são gerenciadas? & Experiência vivida & $\mathrm{x}$ & \\
\hline \multirow{2}{*}{ Econômica } & Gestão fundiária & Arquivos & $\mathrm{x}$ & $\mathrm{x}$ \\
\hline & Gestão da mais-valia & Dados imobiliários & $\mathrm{x}$ & $\mathrm{x}$ \\
\hline Ambiental & $\begin{array}{l}\text { Quais são as dimensões } \\
\text { envolvidas? }\end{array}$ & Documentos oficiais & $\mathrm{x}$ & $\mathrm{x}$ \\
\hline Política & $\begin{array}{l}\text { Quem lucra com as } \\
\text { operações urbanas? }\end{array}$ & Imprensa e arquivos & $\mathrm{x}$ & $\mathrm{x}$ \\
\hline \multirow{6}{*}{ Social } & $\begin{array}{l}\text { Miscigenação social e de } \\
\text { tipos de uso }\end{array}$ & $\begin{array}{l}\text { Documento de } \\
\text { criação }\end{array}$ & $\mathrm{x}$ & \\
\hline & Habitação social & $\begin{array}{l}\text { Documento de } \\
\text { implantação }\end{array}$ & & $\mathrm{x}$ \\
\hline & Transporte e mobilidade & Orçamento & $\mathrm{x}$ & $\mathrm{x}$ \\
\hline & Escala humana & $\begin{array}{l}\text { "Exposição de } \\
\text { motivos" }\end{array}$ & $\mathrm{x}$ & \\
\hline & Participação das minorias & Atas de reuniões & $\mathrm{x}$ & $\mathrm{x}$ \\
\hline & Escuta das minorias & Arquivos & & $\mathrm{x}$ \\
\hline
\end{tabular}

Quadro I-Quais dados são necessários para medir a qualidade urbana? Fonte: FONSECA, Carolina M., 2016

\section{ELABORAÇÃO DE DADOS A PARTIR DE FONTES MULTIVARIADAS PARA O ESTUDO DA APROPRIAÇÃo DO TERRITÓRIO}

O objetivo de uma parte do trabalho realizado durante a pesquisa foi o de analisar as dinâmicas de apropriação do território para compreender as transformações das zonas naturais e antrópico-naturais durante 60 anos de urbanização da Região dos Lagos, no estado do Rio de Janeiro. Essa análise parte de um olhar ao mesmo tempo histórico e espacial, com o objetivo de lançar hipóteses que determinaram a localização dos loteamentos residenciais e, em seguida, favorecer ou não a urbanização no seu entorno. Essas escolhas foram, evidentemente, realizadas de acordo com as políticas urbanas locais, regionais e nacionais, e seus atores sociais. Numerosos regulamentos, em diferentes níveis, favoreceram a extensão urbana, e outros, mais recentes, modificaram a forma de construir a cidade através do adensamento de loteamentos. Esses dois processos são, portanto, fenômenos ligados à urbanização que conduz ao consumo dos espaços naturais e antrópico-naturais em escala regional, passando à escala municipal, até a escala urbana e a do lote com o exemplo mais concreto da comuna de Araruama. A extensão urbana e o adensamento nos colocam questões sobre a sustentabilidade desses espaços em uma região onde o hábitat, sob a forma de loteamentos destinados à utilização temporária, se revela predominante.

A construção metodológica para estudar a dinâmica de transformação dos 
espaços naturais e antrópico-naturais, devido à urbanização, necessitou de prévia organização dos dados, que estavam distribuídos em diversos documentos, organismos e instituições, em diferentes suportes, escalas e períodos. Um dos primeiros elementos trabalhados foram os dados de ocupação do solo da região.

Outro aspecto que merece atenção é a possibilidade de realizar comparações através da evolução urbana com dados estatísticos de outras instituições, como, por exemplo, o Instituto Brasileiro de Geografia e Estatística - IBGE. A descentralização das responsabilidades na produção e difusão dos dados no país, de um lado, permite, a especialização das instituições, mas, de outro, envolve perda considerável em termos de acompanhamento das mudanças ambientais. Uma das dificuldades foi a de identificar qual dado era o mais confiável e aquele que propiciaria o maior número de análises possível. Colocamos assim a seguinte questão: como utilizar dados multivariados disponíveis para analisar o fenômeno de urbanização em diversas escalas temporais e espaciais?

O objetivo aqui é identificar quais dados foram mobilizados para compor a evolução da ocupação do solo da Região dos Lagos (figuras I e 2) e a evolução da implantação de loteamentos por período e localização, além do desafio de elaborar novos dados a partir de diferentes fontes:

- CILSI - O Consórcio Intermunicipal Lagos São João reúne os I2 municípios da bacia hidrográfica Lagos São João e trabalha para a gestão ambiental dos recursos naturais existentes nos municípios sob sua responsabilidade. Os arquivos disponíveis no CILSJ contêm elementos sobre a ocupação do solo para o ano de $1998^{\text {I8 }}$.

- INEA - O Instituto Estadual do Ambiente do Rio de Janeiro coloca à disposição em seu site todos os arquivos da obra intitulada $O$ estado do ambiente em que são analisados os aspectos do meio ambiente do estado do Rio de Janeiro ${ }^{\text {I9 }}$. O interesse por esses arquivos foi a ocupação e uso do solo da Região dos Lagos para o ano de 2010.

- IBGE - O Instituto Brasileiro de Geografia e Estatística ${ }^{20}$ coloca à disposição dados no formato .shp. Outros dados no formato .dgn disponíveis no site foram também utilizados para compor o mapa de ocupação do solo dos anos I960. Para elaborar esse mapa, dois métodos foram utilizados: a conversão dos elementos no formato .dgn para o formato .shp, e a digitalização de algumas classes de ocupação do solo do mapa topográfico correspondente. O IBGE dispõe também da malha dos setores do censo.

- INPE - O Instituto Nacional de Pesquisas Espaciais coloca à disposição para download, gratuitamente, desde os anos I970, numerosas imagens de satélite do Bra$\mathrm{sil}^{2 \mathrm{I}}$. São imagens de resoluções variáveis (de $2 \mathrm{~m}$ a $80 \mathrm{~m}$ ) captadas por diferentes

I8 CILSJ - Consórcio Intermunicipal Lagos São João. Disponível em: <http://www.lagossaojoao.org.br/index-2. html>. Acesso em: out. 2016.

I9 INEA - Instituto Estadual do Ambiente do Rio de Janeiro. Disponível em: <http://www.inea.rj.gov.br/Portal/ index.htm>. Acesso em: out. 2016.

20 IBGE - Instituto Brasileiro de Geografia e Estatística. Disponível em: <http://www.ibge.gov.br/home>. Acesso em: out. 2016.

2I INPE - Instituto Nacional de Pesquisas Espaciais. Disponível em: <http://www.dgi.inpe.br/siteDgi/portugues/ index.php>. Acesso em: out. 2016. 
satélites. Utilizamos a imagem de outubro de 1986 do Landsat-5 TM, e, em seguida, um trabalho de sensoriamento remoto foi necessário para elaborar o mapa de ocupação do solo de I986. Os elementos detectados foram convertidos no formato .shp para sua utilização em um software de SIG a fim de possibilitar a comparação entre os diferentes períodos dos mapas de ocupação do solo e as análises das dinâmicas de consumo dos espaços naturais e antrópico-naturais.
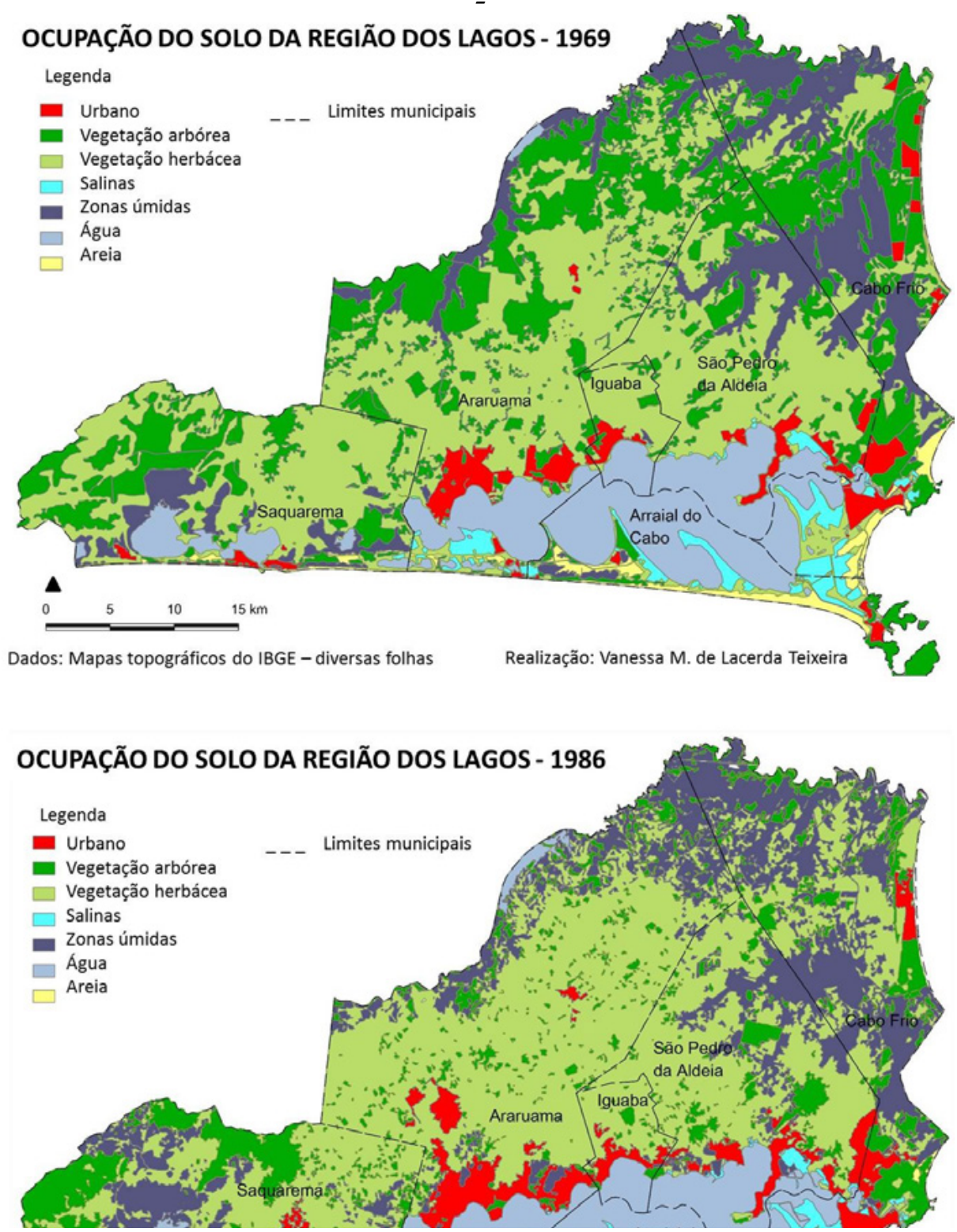

Figura I - Ocupação do solo da Região dos Lagos - I969 e I986. Fonte: TEIXEIRA, Vanessa M. de Lacerda, 2016 

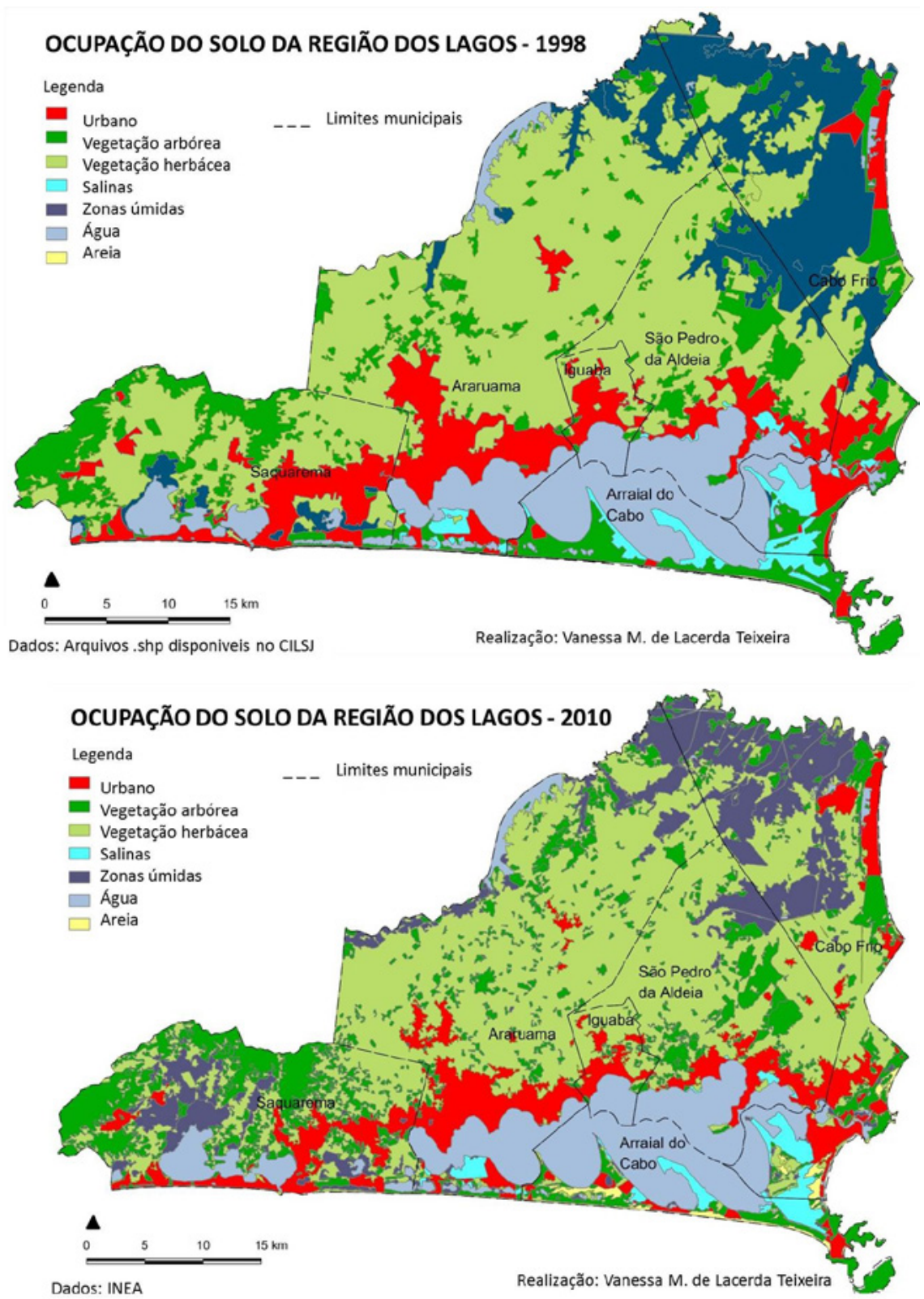

Figura 2 - Ocupação do solo da Região dos Lagos - I998 e 20Io. Fonte: TEIXEIRA, Vanessa M. de Lacerda, 2016

Diversos estudos utilizaram diferentes tipos de imagens e fontes de material 
para compor mapas de ocupação do solo ${ }^{22}$. Herzog e Lausch ${ }^{23}$ realizaram um estudo comparativo de aplicação das métricas da paisagem e o impacto da escala, da resolução espacial e temporal. Eles concluíram que, na digitalização de um mapa ou de uma fotografia aérea, resultando em um dado vetorial, a informação espacial é interpretada e generalizada, pois no mapa-base do trabalho uma interpretação já havia sido realizada pelo pesquisador, enquanto, na interpretação de uma imagem de satélite, há menos generalização e a informação espacial é conservada. Gregory ${ }^{24}$ assinala que existem problemas de precisão no momento da utilização do SIG, no que diz respeito à escala, como o método utilizado para captar o primeiro dado (digitalização, sensoriamento remoto, o escaneamento de uma imagem e em seguida a sua digitalização manual). Ele indica que diversas informações podem ser perdidas em termos de precisão da fonte do dado original durante o seu tratamento. Esse foi um dos desafios na utilização de dados multivariados para compor o conjunto de mapas de ocupação do solo.

\section{Plantas de loteamentos do município de Araruama}

Os arquivos da Prefeitura de Araruama representam também uma fonte histórica sobre a morfologia urbana na escala local, tal como concebida no momento de sua aprovação. Essas plantas, datadas de várias épocas, foram úteis na compreensão da produção da cidade de Araruama, na localização dos loteamentos, e para os interesses da Prefeitura (atores sociais), principalmente aquele de adquirir o máximo de superfície urbana no momento da aprovação dos loteamentos para compor seu patrimônio municipal ${ }^{25}$. No entanto, a dificuldade na organização dos dados depende também do nível de organização institucional na qual esses dados são produzidos e armazenados. Diversas plantas de loteamentos utilizadas para mostrar a evolução urbana de Araruama estavam em péssimas condições de conservação, enroladas em tubos e muitas vezes rasgadas. A chance de encontrá-las fotografadas por um técnico facilitou o trabalho de coleta e análise, mas com uma perda muito grande de informações.

22 RUDOLPHO, Lucas da Silva et al. Aplicação de técnicas de geoprocessamento e métricas da paisagem na análise temporal da cobertura florestal da Bacia do Ribeirão Fortaleza em Blumenau/SC. In: SIMPÓSIO BRASILEIRO DE SENSORIAMENTO REMOTO - SBSR, I6., Anais..., Foz do Iguaçu, 20I3, I3 a I8 de abril, p. I.742-I.749; LAUSCH, Angela; HERZOG, Felix. Applicability of landscape metrics for the monitoring of landscape change: issues of scale, resolution and interpretability. Ecological Indicators, n. 2, Elsevier, 2002, p. 3-I5.

23 HERZOG, Felix; LAUSCH, Angela. Supplementing land-use statistics with landscape metrics: some methodological considerations. Environmental Monitoring and Assessment, v. 72, Issue I, Kluwer Academic Publishers, 200I, p. 37-50.

24 GREGORY, Ian. A place in history: a guide to using GIS in historical research. Oxford: Oxbow Books, 2003.

25 O Código de Urbanismo e Construção de Araruama regulamenta a obrigação da cessão à Prefeitura, pelo proprietário, de uma porcentagem da superfície do loteamento a ser aprovado, o que aumenta consideravelmente o patrimônio municipal. 


\section{Evolução do município de Araruama entre I940 e I990}

Costa $^{26}$ apresenta a evolução urbana de Araruama entre I940 e I990 através da implantação de loteamentos. O trabalho metodológico do seu estudo compreende uma lista por período (I950-I955; I956-I973; I974-I990) de todos os loteamentos implantados por data de aquisição da terra, data de implantação e superfície total do loteamento e sua localização por bairro. Ele estrutura também uma evolução baseada no papel da evolução imobiliária no município e seus principais atores de investimento (agentes particulares, agências imobiliárias, proprietários de terras e parcerias proprietários de terras-agências imobiliárias) a fim de se compreender o papel desses atores na transformação do uso do solo. Costa não realizou um estudo espacial do desenvolvimento urbano do município a partir de seus dados de pesquisa, o que seria fundamental para a continuidade do trabalho científico iniciado por ele em I993. Assim, os loteamentos recenseados entre I940 e I990 foram geolocalizados por bairros em um programa de SIG (QuantumGIS) a fim de se fazer referência às zonas urbanas dos anos I960 e I990 (figura 3).

Essa tese utilizou numerosos dados brasileiros para a compreensão das dinâmicas espaciais e questões ambientais associadas. Essa tarefa, terminada em diferentes escalas de análise - regional, municipal/urbana -, coloca em questão a organização das bases de dados brasileiros. Esses dados, distribuídos em diferentes instituições em diferentes suportes e escalas espaciais e temporais, tornam complexa a análise e implicam uma sólida metodologia, especialmente para as bases de ocupação do solo.

26 COSTA, Claudio Barbosa da. O negócio da terra - a expansão urbana de Araruama I940-I990. Dissertação (Mestrado em Geografia). Instituto de Geociências, Universidade Federal do Rio de Janeiro, I993. 

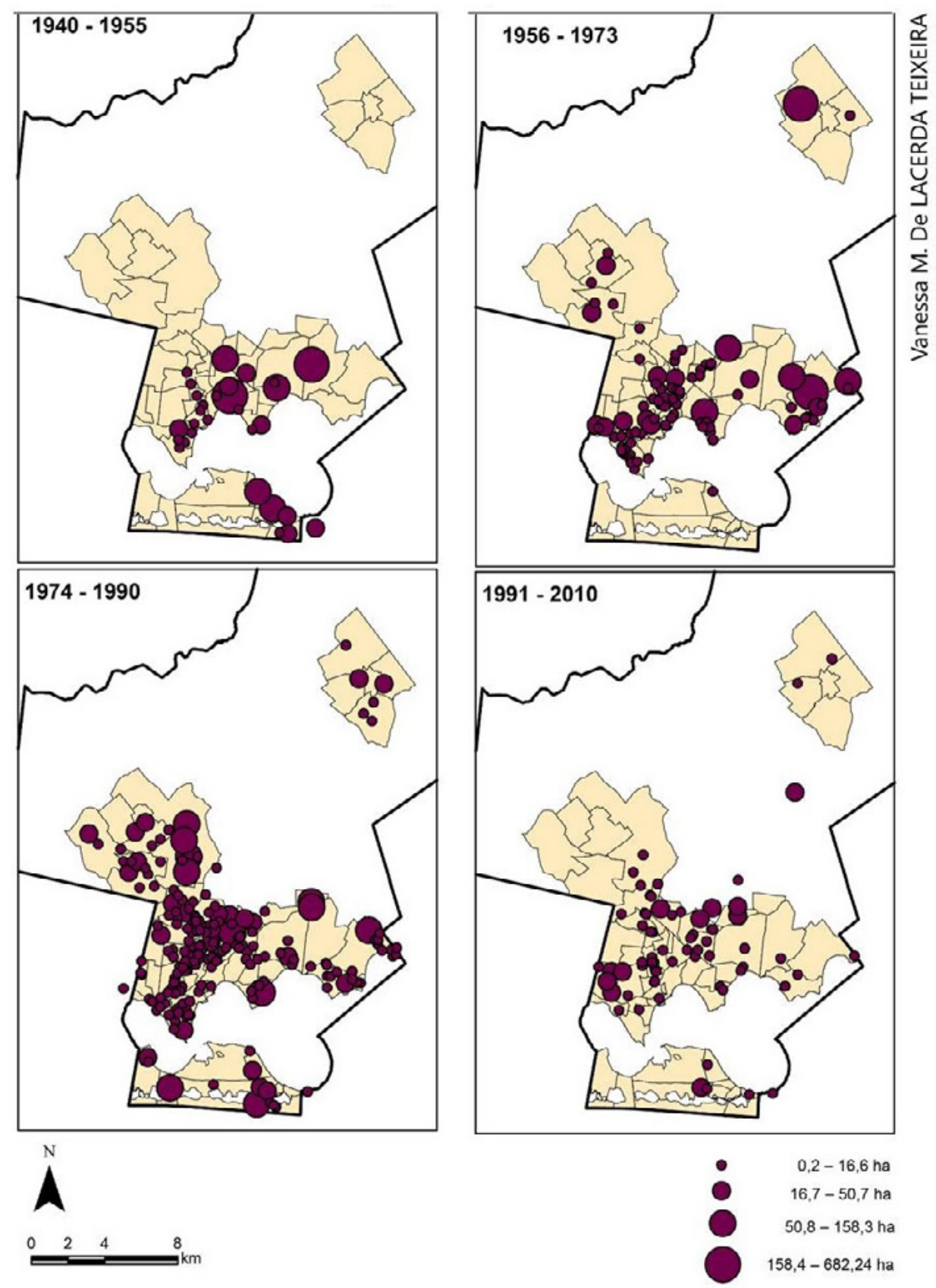

Dados: Costa (1993); Secretaria de Obras e Urbanismo de Araruama

Figura 3 - Evolução da superfície e localização dos loteamentos no município de Araruama (hectares) de I940 a 20I0. Fonte: TEIXEIRA, Vanessa M. de Lacerda, 2016 


\section{Discussões}

O contexto da gestão territorial brasileira e a experiência do trabalho de campo mostraram que a eficácia do planejamento necessita da organização das bases de dados, que atualmente não existem de maneira sistemática, levando em consideração informações sobre a dinâmica de evolução. Os cinco municípios da região e o município de Araruama não possuem um sistema de informação reunindo dados para o acompanhamento das mudanças. A metodologia usada através de um SIG mostrou que é possível avaliar as pressões de acordo com a evolução urbana e ambiental, pois os dados podem ser reutilizados em outras análises comparativas. O principal problema identificado na região, também presente em outros municípios brasileiros, está ligado ao fato de que a maioria deles não dispõe de pessoal e de meios técnicos para aplicar um sistema de gestão dos dados compartilhado do território.

A aplicabilidade dos dados coletados em um SIG se mostrou bastante importante nesse contexto multivariado em razão da possibilidade de sua reutilização em outros períodos (por exemplo, através da atualização de dados antigos a partir de ortofotos recentes) e, sobretudo, pela possibilidade de comparações espaciais e históricas. Outro aspecto é a interligação possível entre o território, os atores sociais e os meios, que são os três níveis de análise propostos neste artigo para estudar a produção da cidade no seu contexto multiescalar, em termos não só espaciais, mas também temporais.

\section{CONCLUSÃo}

Os três estudos da produção da cidade apresentados aqui se desenvolvem em três dimensões diferentes. De acordo com a abordagem de cada um, os questionamentos variam, mas são complementares. É então necessário elaborar e/ou coletar dados específicos. Por exemplo, a abordagem territorial depende da análise das lógicas dos atores e dos meios que eles mobilizam aplicados à cidade. Esses dois últimos níveis de análise são secundários, mas necessários para a abordagem territorial. Da mesma forma, os aspectos jurídicos permitem associar o ator ao território. Para compreender a produção da cidade, é preciso, então, mobilizar essas três dimensões e utilizar os diferentes dados produzidos através da cartografia, dos arquivos ou dos regulamentos jurídicos.

\section{SOBRE OS AUTORES}

FABIEN MAZENOD é doutor em Geografia e Planejamento pela Université Jean Moulin (Lyon 3) e pesquisador associado ao Laboratório UMR 5600 Environnement Ville Société.

E-mail: fabien.mazenod@gmail.com 
CAROLINA MORETTI FONSECA é doutoranda em Geografia e Planejamento na Université Jean Moulin - Lyon 3. UMR 5600 Environnement Ville Société. E-mail: morettifonseca@uol.com.br

VANESSA MOURA DE LACERDA TEIXEIRA é doutora em Geografia e Planejamento pela Université Jean Moulin (Lyon 3) e pesquisadora associada ao Laboratório UMR 5600 Environnement Ville Société. E-mail: vanessamlt2@gmail.com

\section{REFERÊNCIAS BIBLIOGRÁFICAS}

ARCHIVI D'IMPRESA. Ministero dei beni e delle attivita' culturali e del turismo. Sistema Archivistico Nazionale-SAN. Disponível em: <http://www.imprese.san.beniculturali.it/web/imprese/home;jsessionid=2792B854D5C3D35B22I7E8Co5D2A4D5A.sanimprese_JBOSS >. Acesso em: out. 2016.

BARBARINO-SAULNIER, Natalia. De la qualité de vie au diagnostic urbain, vers une nouvelle méthode d'évaluation: le cas de la ville de Lyon. Thèse (Doctorat en Géographie). Sous la direction de Franck Scherrer. Université de Lyon, Lyon, 2005.

BARTOLINI, Francesco. Roma Borghèse: la casa e i ceti medi tra le due guerre. Rome: Laterza, $200 I$. BOINO, Paul. La production de la ville. Paris: Éditions Parenthèses, 2009.

BOURDEAU-LEPAGE, Lise. Regards sur la ville. Paris: Economica, $20 \mathrm{I2}$.

COSTA, Claudio Barbosa da. O negócio da terra: a expansão urbana de Araruama I940-I990. Dissertação (Mestrado em Geografia). Instituto de Geociências, Universidade Federal do Rio de Janeiro, I993.

CUNHA, Antonio da; GUINAND, Sandra. Qualité urbaine, justice spatiale et projet. Lausanne: Presses Polytechniques et Universitaires Romandes, 20I4.

DOTI, Gerardo; MARINO, Angela. La Banca d'Italia e l'attività edilizia per Roma capitale: il progetto di ricerca. Roma moderna e contemporanea, n. 3, 2002.

DUMONT, Marc; ANDRIEU, Dominique. Qualité urbaine et ville durable à l'épreuve du renouvellement urbain. L'exemple du Grand Projet de Ville Malakoff Pré Gauchet à Nantes. Norois, n. I98, 2066.

FERNANDES, Edésio; VARLEY, Ann. Illegal cities: law and urban change in developing countries. London: Zed Books, I998.

FONSECA, Carolina M. Les enjeux fonciers de la production de la ville contemporaine et les outils juridiques à service de l'aménagement urbain: étude comparative entre les opérations urbaines “Confluence”, à Lyon et “Água Espraiada”, à São Paulo, entre 2001 et 2013. Tese (Doutorado em andamento). Lyon: Université Jean Moulin (Lyon 3), 2016.

GAUTHIEZ, Bernard; BURGEL, Guy. Espace urbain: vocabulaire et morphologie. Paris: Centre des Monuments Nationaux, 2003.

GREGORY, Ian. A place in history: a guide to using GIS in historical research. Oxford: Oxbow Books, 2003. GUMUCHIAN, Hervé (Coord.). Les acteurs, ces oubliés du territoire. Paris: Anthropos, 2003.

HERZOG, Felix; LAUSCH, Angela. Supplementing land-use statistics with landscape metrics: some methodological considerations. Environmental Monitoring and Assessment, v. 72, Issue I, Kluwer Academic Publishers, 200I, p. 37-50. 
INPE - Instituto Nacional de Pesquisas Espaciais. Disponível em: <www.inpe.br >. Acesso em: out. 2016.

KLEINSCHMAGER, Richard; PUMAIN, Denise; PAQUOT, Thierry. Dictionnaire La ville et l'urbain. Paris: Economica, 2006.

LAUSCH, Angela; HERZOG, Felix. Applicability of landscape metrics for the monitoring of landscape change: issues of scale, resolution and interpretability. Ecological Indicators, n. 2, Elsevier, 2002, p. 3-I5. LUSSAULT, Michel; LEVY, Jacques. Dictionnaire de la géographie et de l'espace des sociétés. Tours: Belin, 2003. MAZENOD Fabien. Fabriquer la Rome fasciste. L'action de l'Istituto Nazionale delle Assicurazioni (INA). Investisseur immobilier et financeur de l'aménagement urbain. Tese (Doutorado). Lyon: Université Jean Moulin (Lyon 3), 20I4. Disponível em: <www.theses.fr/20I4LYO30042〉. Acesso em: out. 2016.

OLBERTZ, Karlin. Operação Urbana Consorciada. Belo Horizonte: Fórum, 2012.

RENARD, Vincent. Plans d'urbanisme et justice foncière. Paris: Presses Universitaires de France, I992.

RUDOLPHO, Lucas da Silva et al. Aplicação de técnicas de geoprocessamento e métricas da paisagem na análise temporal da cobertura florestal da Bacia do Ribeirão Fortaleza em Blumenau/SC. In: SIMPÓSIO BRASILEIRO DE SENSORIAMENTO REMOTO - SBSR, I6., Anais..., Foz do Iguaçu, 20I3, I3 a I8 de abril, p. I.742-I.749.

SILVA, José Alfonso da. Direito urbanístico brasileiro. São Paulo: Malheiros Editores, 2012.

SOLER-COUTEAUX, Pierre; CARPENTIER, Elise. Droit de l'urbanisme. Paris: Dalloz, 2013.

TEIXEIRA Vanessa M. de L. L'urbanisation autour de la lagune Araruama, etat de Rio de Janeiro, Brésil: dynamiques spatiales et enjeux environnementaux. Tese (Doutorado). Lyon: Université Jean Moulin (Lyon 3), 20I6. Disponível em: 〈www.theses.fr/sI5523I〉. Acesso em: out. 2016.

WACKERMANN, Gabriel; BATTIAU, Michel. Dictionnaire de géographie. Paris: Ellipses Marketing, 2005. ZEPF, Marcus (Coord). Concerter, gouverner et concevoir les espaces publics urbains. Lausanne: Presses Polytechniques et Universitaires Romandes, 2004. 